\title{
Case Report: Aicardi Syndrome presenting as Cleft Lip and Palate
}

\author{
Danielle Weidman ${ }^{1}$ and Juan Pablo Appendino ${ }^{2 *}$ \\ ${ }^{1}$ Paediatric Resident, The Hospital for Sick Children, University of Toronto, Canada \\ ${ }^{2}$ Department of Pediatrics, University of Calgary, Canada
}

Submission: March 02, 2017; Published: May 30, 2017

*Corresponding author: Juan Pablo Appendino, Clinical Associate Professor, Department of Paediatrics, Cumming School of Medicine, University of Calgary, Pediatric Epilepsy and Child Neurology, Alberta Children's Hospital 2888 Shaganappi Trail NW, Calgary, AB T3B 6A8, Tel: 403-955-7816; Fax: 403-955-7609; Pager: 403-212-8223 \#14691; Email: jp.appendino@albertahealthservices.ca

\begin{abstract}
Aicardi syndrome (AS) is an unusual neurological disorder that was originally described in 1965 by Dr. Jean Aicardi. This disorder is characterized by a triad of abnormalities: agenesis of the corpus callosum, chorio retinal lacunae, and infantile spasms. There are infrequent reports of cleft lip and palate in patients with AS. This report details a case of a patient with AS who presented with left-sided cleft lip and palate and right eye coloboma to her pediatrician; however, the diagnosis of AS was not suspected until later when the she presented with Infantile Spasms. The discussion will focus on the existing literature of AS with cleft lip and palate and ophthalmological findings offering a learning point to the pediatric community in regards with her clinical, neuroimaging and neurophysiological findings for an earlier and appropriate diagnosis.
\end{abstract}

\section{Introduction}

Aicardi syndrome (AS) is a relatively rare disease that was originally described in 1965 by a French neurologist named Dr. Jean Aicardi.AS consists of a classically described triad including partial or total agenesis of the corpus callosum, unilateral or bilateral chorio retinal lacunaes, and infantile spasms [1]. The causative gene mutation for Aicardi syndrome has not yet been determined although it seems to occur in patients with two X chromosomes as a result of heterozygous defects in an essential $\mathrm{X}$-linked gene or by defects in an autosomal gene with sex-limited expression but not by a copy number variant [2]. Evidence supports early embryonic lethality in hemizygous males. However, there are known cases of Aicardi syndrome in males with XXY karyotype [1-11] and one male with XY karyotype with the classic clinical trial of Aicardi syndrome [12]. The incidence of Aicardi syndrome in the United States is estimated to be 1 per 105,000 births [11] and the know prevalence in Norway is 0.63 per 100,000 females [13] while the prevalence worldwide is approximately several thousand [11].

Despite chorio retinal lacunae being the most common, reliable and pathognomonic findings for this syndrome; other features associated with AS have been described, including cortical malformations, intracranial cysts, focal seizures, mental retardation, vertebral anomalies, cleft lip and palate and eye abnormalities. [1] Cleft lip and palate is believe to occur in about only $3 \%$ of patients with AS [9]; however, it usually first presents to the pediatrician for medical advice. Awareness of AS and its diagnostic challenge among our pediatrician colleaguesis necessary. This case report tries to illustrate the most common diagnostic criteria with the aim to educate our medical community.

\section{Case Report}

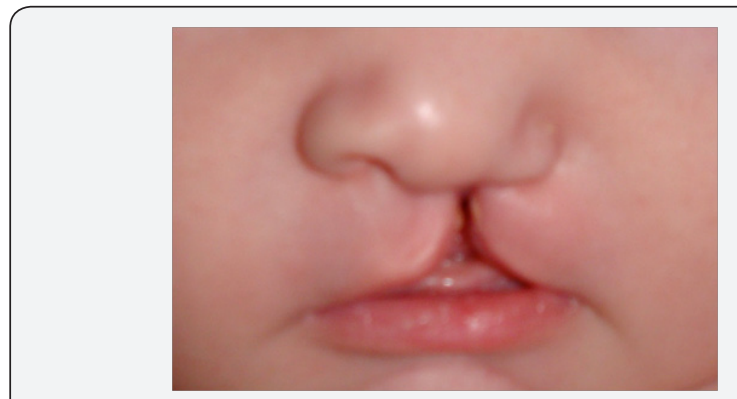

Figure 1: The patient's left-sided cleft lip and palate.

A female infant was born at 41 weeks gestation by induced vaginal delivery to a G1P0 28-year-old mother. The pregnancy was uncomplicated and parents are not consanguineous. Cleft lip was diagnosed prenatally on ultrasound at 29 weeks gestation. At birth, the baby was noted to have a cleft palate as well (Figure 1). Apgar scores were 3 and 8 at 5 and 10 


\section{Open Access Journal of Neurology \& Neurosurgery}

minutes respectively and birth weight was $4.65 \mathrm{~kg}$. She required intubation, suctioning, and a brief stay in NICU due to meconium aspiration and was discharged home on day 1 of life. At 5 weeks of age, the infant presented to the emergency department with a 2-day history of afebrile infantile spasms. At this time, parents also inquired about the right eye coloboma and microphthalmia (Figure 2). She was admitted to hospital, and the diagnostic work-up included ophthalmologic assessment, EEG, and MRI. The pediatric ophthalmologist who saw this patient described unusual fundi with hyperpigmentation of the right optic disc with areas of nummular retinal pigment epithelial scars, and hyperopic error bilaterally. These findings are consistent with chorio retinal lacunae.

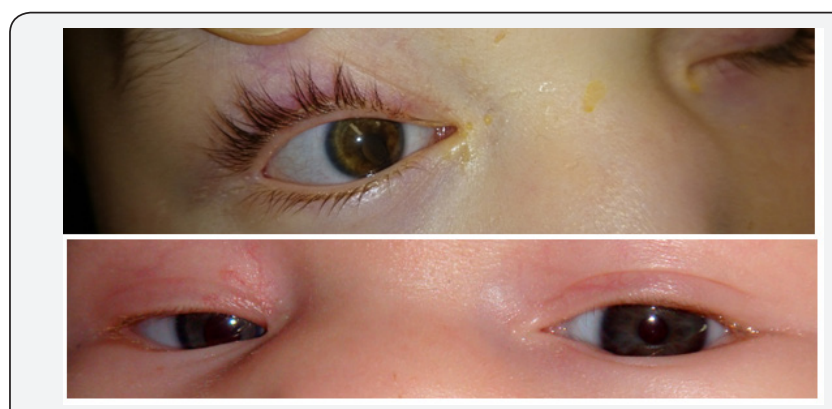

Figure 2: The patient's unilateral right-sided microphthalmia and right eye coloboma. Top) at 3 years of age showing clearly inferiorly oriented coloboma of the right eye. Bottom) at 6 month of age, showing normal left pupil.

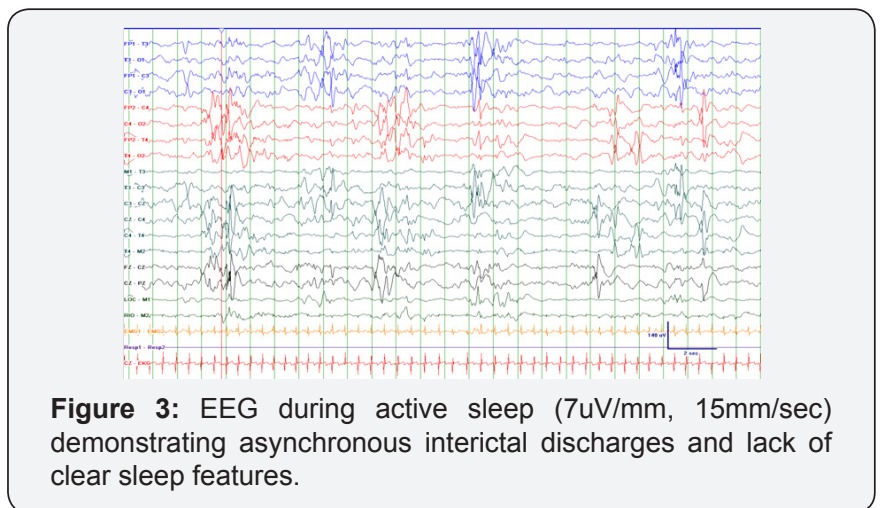

EEG showed intermittent and asynchronous interictal discharges with a lack of clear sleep features. As well, there was midline semi rhythmic theta activity without clinical correlation. From this, it was suggested that this patient has diffusely dysfunctional brain tissue and a dysfunctional or absent corpus callosum (Figure 3). MRI demonstrated complete agenesis of the corpus callosum with heterotopic gray matter lining the lateral ventricles and polymicrogyria of frontal, parietal, and temporal lobes. In addition, it was suggested that the patient may have a Dandy-Walker malformation. A cystic lesion within the right intraorbital optic nerve was seen on MRI, representing the patient's coloboma (Figure 4). Based on the findings consistent with the triad of absent corpus callosum, chorioretinal lacunae, and infantile spasms, the diagnosis of Aicardi syndrome was made. Subsequently, the patient had seizures that were difficult to control, resulting in multiple lengthy hospitalizations. Despite treatment with viga batrin, the infantile spasms persisted. Recently, a classic ketogenic diet was initiated. She requires a special nipple for feeding, but has not had any feeding difficulties and has been gaining weight.

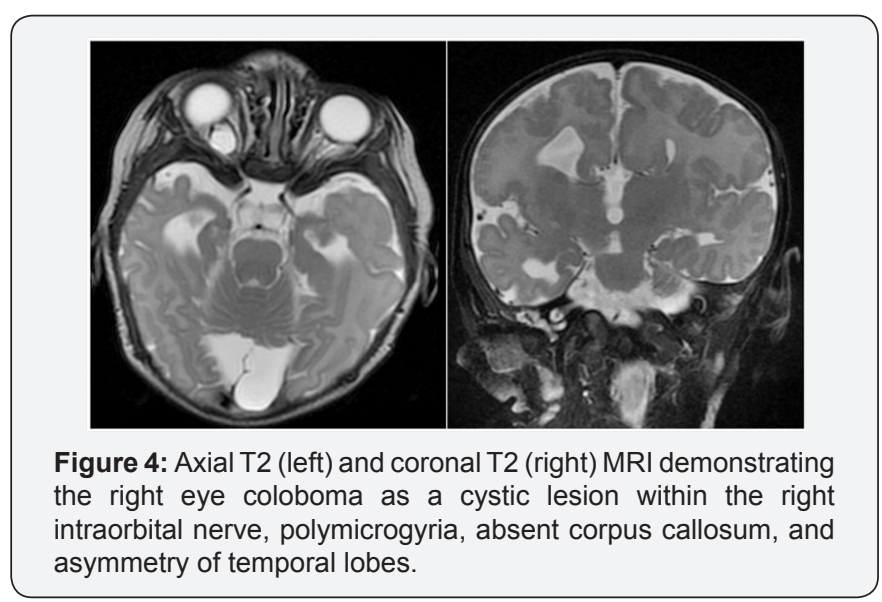

\section{Discussion}

Cleft lip and palate was first reported to be associated with Aicardi Syndrome in 1984 [4]. The case describeda patient with a cleft lip and cleft of posterior palate (side not mentioned), bilateral microphthalmia, and a benign papilloma of the choroid plexus [4]. In 1986, a series of 184 patients with Aicardi syndrome was reported and included two cases of clefts, one of which was previously reported by Robinow et al. [5] Following this, a case of Aicardi syndrome with the classic associated abnormalities was reported in 1987 with a cleft lip and palate and semilobar-type holoprosencephaly [6]. In 1989, a review of 18 females with Aicardi syndrome included one new patient with cleft lip and palate [7]. The fifth case was described in 1990, and the cleft lip and palate in this patient were unilaterally leftsided [8]. In 1993, Umansky et al. [9] reported a case of a patient with Aicardi syndrome, colobomas, and left-sided cleft lip and palate [8]. Of note, pregnancy in this case was complicated by maternal substance abuse [9]. Following this, the seventh case in the literature wasn't reported until 2009 when Steffensen et al. [10] described an infant with Aicardi syndrome and cerebellar migration defects with left-sided cleft lip and palate [10]. This patient deteriorated secondary to a respiratory infection and passed away at 3 months of age [10]. Lastly, in 2011, a case report of a 7-year-old girl with mental retardation and absence of the corpus callosum is presumed to have Aicardi syndrome and reportedly had a cleft palate (side unknown) [11].

Thus, to our knowledge, we report the tenth case of a patient with Aicardi syndrome and cleft lip and palate. We estimate that the incidence of cleft lip and palate in patients with Aicardi syndrome is much less than 3 percent, as estimated in 1994 [9]. The reason for the 16-year gap in reported cases of Aicardi syndrome with cleft lip and palate is unclear. It is possible that this association has become more unusual, or perhaps cases have occurred and have not been reported. 


\section{Open Access Journal of Neurology \& Neurosurgery}

Aicardi syndrome is complex, and the case described above presents a unique learning opportunity. Cleft lip and palate in a patient with Aicardi syndrome is rare, and should be considered part of the possible clinical features of this syndrome. The potential feeding difficulties associated with this congenital deformity may be compounded by the brain abnormalities of this syndrome. In addition, the case illustrates that there is not necessarily a correlation between eye and brain malformations in terms of severity and laterality. Based on our case and the literature, it seems that the facial clefts associated with Aicardi syndrome may have a left-sided trend [14-17].

Neuroimaging plays a key role in the diagnosis of Aicardi syndrome. When a patient presents with seizures and an abnormality of the eyes, it should prompt investigations to search for brain malformations. This may be especially important when the patient also has facial deformities. Since the eyes and the brain develop from the same embryological tissue, an abnormality in one suggests that a more thorough work-up may be warranted. More specifically, when a patient presents with a coloboma and seizures, imaging should be pursued in a timely fashion. There exists a wide range of possible brain abnormalities with many complex combinations and associated abnormalities. An association with a genetic syndrome is something to consider.

\section{Conclusion}

In conclusion, it is unlikely that an earlier diagnosis of Aicardi syndrome in our patient would have changed the outcome. However, had the association of multiple abnormalities been recognized at birth, imaging could have been performed earlier. This may have provided the opportunity to implement supports for parents in advance of the infant's seizure onset. The treatment of Aicardi syndrome is primarily based on seizure management [1], and our patient received appropriate management once her seizures were clinically apparent.

\section{References}

1. Aicardi J (2005) Aicardi syndrome. Brain Dev 27(3):164-71.

2. V Reid Sutton, Ignatia B Van den Veyver (2014) NCBI Bookshelf Gene Reviews- Aicardi Syndrome.
3. Robinow M, Johnson GF, Minella PA (1984) Aicardi syndrome, papilloma of the choroid plexus, cleft lip, and cleft of the posterior palate. J Pediatr 104(3): 404-405.

4. Chevrie, JJ, Aicardi J (1986) The Aicardi Syndrome. In: Pedley TA \& Meldrum BS (Eds.), Recent advances in epilepsy, Volume 3, Edinburgh: Churchill-Livingstone, pp. 189-210.

5. Sato N, Matsuishi T, Utsunomiya H, Yamashita Y, Horikoshi T, et al. (1987) Aicardi syndrome with holoprosencephaly and cleft lip and palate. Pediatr Neurol 3(2): 114-116.

6. Donnenfeld AE, Packer RJ, Zackai EH, Chee CM, Sellinger B, et al. (1989) Clinical, cytogenetic, and pedigree findings in 18 cases of Aicardi syndrome. Am J Med Genet 32(4): 461-467.

7. McPherson E, Jones SM (1990) Cleft lip and palate in Aicardi syndrome. Am J Med Genet 37(3): 318-319.

8. Umansky WS, Neidich JA, Schendel SA (1994) The association of cleft lip and palate with Aicardi syndrome. Plast Reconstr Surg 93(3): 595597.

9. Steffensen TS, Gilbert-Barness E, Lacson A, Margo CE (2009) Cerebellar migration defects in Aicardi syndrome: an extension of the neuropathological spectrum. Fetal Pediatr Pathol 28(1): 24-38.

10. Kumar D, Bindhu S, Shetty S (2011) Aicardi syndrome-a rare case report. Rec Res Sci Tech 3(3): 104-106.

11. Kroner BL, Preiss LR, Ardini MA, Gaillard WD (2008) New incidence, prevalence, and survival of Aicardi syndrome from 408 cases. J Child Neurol 23(5): 531-535.

12. Chappelow AV, Reid J, Parikh S, Traboulsi EI (2008) Aicardi syndrome in a genotypic male. Ophthalmic Genet 29(4): 181-183.

13. Iturralde D, Meyerle CB, Yannuzzi LA (2006) Aicardi syndrome: chorioretinal lacunae without corpus callosum agenesis. Retina 26(8): 977-978.

14. Molina JA, Mateos F, Merino M, Epifanio JL, Gorrono M (1989) Aicardi syndrome in two sisters. J Pediatr 115(2): 282-283.

15. Schrauwen I, Szelinger S, Siniard AL, Corneveaux JJ, Kurdoglu A, et al (2015) A De Novo Mutation in TEAD1 Causes Non-X-Linked Aicardi Syndrome. Invest Ophthalmol Vis Sci 56(6): 3896-3904.

16. Wang X, Sutton VR, Eble TN, Lewis RA, Gunaratne P, et al. (2009) A genome-wide screen for copy number alterations in Aicardi syndrome. Am J Med Genet A 149A(10): 2113-2121.

17. Lund C, Bjørnvold M, Tuft M, Kostov H, Røsby 0, et al. (2015) Aicard syndrome: an epidemiologic and clinical study in Norway. Pediatr Neurol 52(2): 182-186.

\begin{tabular}{l} 
Your next submission with Juniper Publishers \\
will reach you the below assets \\
- Quality Editorial service \\
- Swift Peer Review \\
- Reprints availability \\
- E-prints Service \\
- Manuscript Podcast for convenient understanding \\
- Global attainment for your research \\
- Manuscript accessibility in different formats \\
( Pdf, E-pub, Full Text, Audio) \\
- Unceasing customer service \\
Track the below URL for one-step submission \\
https://juniperpublishers.com/online-submission.php \\
\hline
\end{tabular}

